\title{
A EXTRAFISCALIDADE E A TRIBUTAÇÃO DOS SERVIÇOS DE FORNECIMENTO DE ÁGUA POTÁVEL: POSSIBILIDADES E ALTERNATIVAS
}

\section{EXTRAFISCALITY AND TAXATION OF POTABLE WATER SUPPLY SERVICES: POSSIBILITIES AND ALTERNATIVES}

Recebido: 25.07.2017

Aprovado: 10.11.2017

\author{
Paulo Antônio Caliendo Velloso da Silveira* \\ Paola Mondardo Sartori**
}

RESUMO: Sem a água o corpo humano não sobrevive. Não apenas a espécie humana, mas todos os seres vivos necessitam de água para o funcionamento do seu organismo, seja ele animal ou vegetal. À vista disso, e considerando a problemática atual da escassez de água no país e o recente reconhecimento pela ONU do direito à água potável como um direito humano, fica evidente a urgência na busca por meios de preservação deste elemento indispensável para a manutenção da vida. A tributação com finalidade extrafiscal do fornecimento de água potável é uma dentre as opções de ações governamentais que poderia ser utilizada com objetivo de salvaguardar bem tão precioso. Entretanto, indispensável uma análise mais aprofundada sobre as espécies de tributos possíveis para cumprir esta função, principalmente no que tange às suas vantagens e desvantagens, razão pela qual o presente estudo se demonstra necessário.

Palavras-chave: Água. Tributação. Extrafiscalidade. Direitos fundamentais. Sustentabilidade.

\begin{abstract}
Without water the human body does not survive. It is not just the human species, but all living things need water, animal or vegetable. Having that in mind, and considering the current problem of water scarcity in the country and the recent recognition by the UN of the human right to water and sanitation, it is evident the urgency in the search for ways to preserve this element that is indispensable for maintaining life. The extra-fiscal taxation of the supply of drinking water is one of the many options for governmental actions that could be used with the purpose of safeguarding so precious good. However, a more in-depth analysis of the possible tributary types to fulfill this function is essential, especially as regards their advantages and disadvantages.
\end{abstract}

Keywords: Water. Taxation. Extrafiscality. Fundamental rights. Sustainability.

\footnotetext{
* Professor Permanente do PPGD da PUCRS. Doutor em Direito pela PUCSP. Coordenador do GTAX - Grupo de Pesquisas Avançadas em Direito Tributário da PUCRS. Advogado. E-mail: < p.caliendo@terra.com.br >.

** Mestranda em Direito e Especialista em Direito Público pela Pontifícia Universidade Católica do Rio Grande do Sul. Bolsista integral do Programa de Pós-graduação em Direito da mesma instituição. Advogada. E-mail:< paolamsartori@ gmail.com >.
} 


\section{CONSIDERAÇÕES INICIAIS}

A água, em sua forma pura, é um líquido incolor, inodoro e insípido, sem o qual o corpo humano não sobrevive. Não apenas a espécie humana, mas todos os seres vivos necessitam de água para o funcionamento do seu organismo, seja ele animal ou vegetal. À vista disso, pode-se enunciar que a escassez da água provoca, incontestavelmente, uma limitação no desenvolvimento social e econômico da região afetada, vez que tanto a população encontra-se impossibilitada de utilizar água potável para consumo, quanto a indústria, agricultura e pecuária encontram-se impossibilitados para a utilização na sua produção.

Segundo pesquisa disponibilizada pela Agência Nacional de Águas (ANA), tendo como base dados levantados pela UNESCO, em números aproximados, $97,0 \%$ do total de água existente no mundo é salgada. Dos 3,0\% de água doce existentes no planeta, 2,5\% estão congelados na Antártida, no Ártico e em geleiras, não estando, portanto, disponíveis para o uso humano. Assim sendo, do total de água que encontramos no mundo, o homem e todos os demais seres vivos dependem unicamente da disponibilidade de o, $5 \%$ de água doce (AGÊNCIA NACIONAL DE ÁGUAS, 2009, p. 9). Esta porcentagem ínfima encontra-se disponível em aquíferos, ${ }^{1}$ chuvas, lagos naturais, reservatórios construídos pelo próprio homem e, em menor quantidade, em rios. Dentre essa porcentagem de água doce disponível para consumo, o Brasil ocupa posição privilegiada, possuindo 12\% da disponibilidade hídrica mundial. Esse número ainda se eleva para $18 \%$ caso sejam consideradas as vazões provenientes de território estrangeiro (GRANZIERA, 2015, p. 275).

Através da análise dos dados disponibilizados pela ANA e pela UNESCO, fica evidente a urgência na busca por meios de preservação deste elemento indispensável para a manutenção da vida, vez que o mesmo existe em quantidade extremamente reduzida no meio ambiente. Ainda, é também visível a importância do papel brasileiro na proteção deste recurso natural, visto que o Brasil é um dos principais detentores das reservas mundiais de água doce disponíveis. Dessa forma, importante termos em mente que o descaso com a utilização da água e sua consequente escassez em território nacional afeta não apenas nós, brasileiros, mas a população mundial como um todo, razão pela qual imperiosa a adoção urgente de ações governamentais com objetivo de salvaguardar bem tão precioso e, portanto, perceptível a necessidade de um estudo aprofundado quanto às possibilidade jurídicas existentes nesta área.

\section{A ÁGUA E O DIREITO}

Antes de adentrarmos mais especificamente no tema sobre a tributação com finalidade extrafiscal com objetivo de induzir condutas protetivas ao recurso natural

\footnotetext{
1 Aquíferos são reservatórios naturais de água subterrânea. Diferentemente dos rios e lagos, que se renovam e se autodepuram em poucos dias, os aquíferos não possuem essa capacidade, razão pela qual é de extrema preocupação o uso dessas águas sem considerar a natureza potencialmente poluidora de determinadas atividades. O Brasil possui em seu território o maior reservatório de água doce do mundo, o Aquífero Guarani, que, em menor escala, também adentra território Argentino, Uruguaio e Paraguaio. (GRANZIERA, Maria Luiza Machado. Direito Ambiental. São Paulo: Atlas, 2015, p. 302-305).
} 
em comento, imprescindível discorrermos, mesmo que brevemente, sobre o direito fundamental a este bem e a maneira como sua regulação se dá em solo nacional, para posteriormente nos aprofundarmos nas possibilidades de sua tributação.

\subsection{O direito humano à água potável e o dever do Poder Público em garanti- 10.}

A Assembleia Geral da ONU, em 26 de julho de 2010, declarou o reconhecimento do "direito à água potável e ao saneamento como um direito humano essencial para o pleno desfrute da vida e de todos os direitos humanos" (SARLET; FENSTERSEIFER, 2014, p.274). O reconhecimento deste direito como humano se funda na importância que este recurso natural tem para a garantia dos demais direitos humanos reconhecidos, tais quais a vida, a saúde, o meio ambiente ecologicamente equilibrado, entre outros.

ComobemexpõeIngoSarleteTiagoFensterseiferemsuaobra,adeclaraçãodaONUevidencia o reconhecimento de interdependência e indivisibilidade que deve permear o tratamento dos direitos humanos e fundamentais. Afinal, como será possível garantir a saúde e principalmente a vida de um ser humano se o mesmo não possuir acesso ao elemento que garante sua subsistência? Como será possível garantir um meio ambiente ecologicamente equilibrado para uma sociedade se não houver água potável para que este ambiente cresça e se desenvolva? Evidente, portanto, a dependência de todos estes direitos humanos e fundamentais para com o direito à água potável, razão pela qual a proteção deste direito necessita de especial atenção.

O direito à água potável, diferentemente do que ocorre em outros países, ${ }^{2}$ não está previsto expressamente em nossa Constituição, ${ }^{3}$ vez que a Carta Magna trata sobre o tema apenas quando enumera os bens da União e dos Estados. Infraconstitucionalmente, a Lei no 9.433/97, que institui a Política Nacional de Recursos Hídricos, define a água como bem de domínio público e como recurso natural limitado, dotado de valor econômico. Percebe-se, portanto que a água, no ordenamento jurídico brasileiro, ainda é tratada mais como um bem de valor econômico do que como um bem essencial à manutenção da vida.

Pode-se argumentar, entretanto, que por força do princípio contido no art. $4^{\circ}$, inciso II, da CF/88, que proclama que a República Federativa do Brasil se rege pela prevalência dos direitos humanos, o direito à água potável estaria tutelado, vez que reconhecido internacionalmente pela ONU como direito humano essencial. Entretanto, não obstante o reconhecimento internacional deste direito humano, o direito à água

2 Exemplos de Constituições que preveem expressamente o direito à água potável como direito fundamental são as da Bolívia (art. 20, III), que afirma que o acesso à água potável e ao saneamento básico é um direito humano, e a do Equador (art. 12), que declara que o acesso à água é um direito fundamental e irrenunciável.

3 Desde 2007 tramita no Congresso Nacional a Proposta de Emenda à Constituição no 39 que propõe a modificação da redação do art. 6o da Constituição Federal de 1988 com objetivo de incluir a água como um dos direitos sociais citados no caput deste artigo. Entretanto, até hoje esta proposta permanece em tramitação e, portanto, o direito água segue não positivado na Constituição brasileira. 
potável ainda assim seria digno de tutela pela Constituição brasileira, na medida em que, como já mencionamos, para que se garanta os demais direitos constitucionalmente previstos e a própria dignidade da pessoa humana, imprescindível que se garanta a todos o acesso à água potável e ao saneamento básico. Evidente, portanto, o caráter fundamental deste direito, podendo-se defender, inclusive, sua previsão implícita no texto constitucional.

Ainda que se negasse o reconhecimento do direito fundamental à água potável na Constituição Federal brasileira, ou ainda o seu reconhecimento em razão do art. $4^{\mathbf{0}}$, inciso II, da Carta Magna, a proteção e controle da utilização deste bem permaneceria considerada um dever do poder público por força do art. 225 da CF/88. Isso porque a manutenção e proteção da água é indispensável para que se garanta um meio ambiente ecologicamente equilibrado e, consequentemente, a sadia qualidade devida dos cidadãos.

Da leitura do inciso V, §1ํㅜ do art. 225 da Constituição brasileira, ${ }^{4}$ extrai-se o dever do poder público em controlar a produção e comercialização de substâncias que comportem risco para a vida, a qualidade de vida e o meio ambiente, inserindo-se aqui, claramente, o dever do poder público no controle do uso da água potável com vistas a garantir, dessa forma, a qualidade de vida de todos os indivíduos e também a preservação de um meio ambiente ecologicamente equilibrado.

Os direitos fundamentais, inclusive o direito fundamental ao meio ambiente ecologicamente equilibrado, que, de certa forma, engloba o direito fundamental à água potável, é um direito-dever. Assim sendo, o cidadão e o Estado são simultaneamente credores e devedores desta tutela. Para tanto, este dever fundamental de proteção pode ter tanto uma função defensiva, quanto uma função prestacional. Como bem explana Ingo Sarlet e Tiago Fensterseifer, os deveres fundamentais de proteção do meio ambiente exigem:

[...] tanto a adoção de medidas prestacionais necessárias à salvaguarda do equilibro ecológico, como ocorre na hipótese de medidas voltadas à conservação do patrimônio ambiental ou à reparação de um dano ecológico causado, quanto de medidas negativas, o que ocorre no caso de impedir o particular de realizar determinada atividade que, mesmo potencialmente - ante o princípio da precaução -, possa acarretar dano ambiental, como desmatar a área de mata ciliar ou despejar produto químico no córrego de um rio (2013, p. 245).

Deste modo, cabe ao Estado adotar medidas prestacionais e negativas para a proteção do direito à água potável e, consequentemente, do direito à vida e do direito ao meio ambiente ecologicamente equilibrado. Dentre as medidas prestacionais possíveis está a concessão de incentivos fiscais ou a incidência de tributos sobre este recurso natural, de maneira a se utilizar a extrafiscalidade para estimular o uso consciente da água pela população, questão essa que será melhor aprofundada no decorrer deste trabalho.

\footnotetext{
4 Art. 225. Todos têm direito ao meio ambiente ecologicamente equilibrado, bem de uso comum do povo e essencial à sadia qualidade de vida, impondo-se ao Poder Público e à coletividade o dever de defendê-lo e preservá-lo para as presentes e futuras gerações. $§ 1^{\circ}$ Para assegurar a efetividade desse direito, incumbe ao Poder Público: [...] V controlar a produção, a comercialização e o emprego de técnicas, métodos e substâncias que comportem risco para a vida, a qualidade de vida e o meio ambiente.
} 


\subsection{Domínio e outorga de direito de uso: como regulamentamos a água no Brasil?}

Como bem expõe Maria Luiza Machado Granziera, a água possui características muito específicas, vez que ao mesmo tempo em que "constitui um recurso ambiental, tutelado pelo Poder Público, por sua importância ao consumo humano eaos ecossistemas, é um insumo de processos produtivos, como a energia elétrica ea indústria" (GRANZIERA, 2015, p. 276). Dessa forma, possui tanto valor de bem ambiental, que deve ser protegido, como valor de bem econômico, passível de utilização para tal fim. Imperioso, portanto, que sua utilização seja regulamentada para fins econômicos, porém sempre tendo em vista sua proteção.

A Constituição Federal trata da água quando enumera os bens da União e dos Estados, nos seus artigos 20 e 26. As águas pertencem à União quando estiverem em terrenos de seu domínio (como, por exemplo, uma unidade de conservação por ela instituída), quando banharem mais de um Estado, quando servirem de limite com outros países ou quando se estenderem em território estrangeiro ou dele prevenirem, bem como os terrenos marginais e as praias fluviais. Ainda, pertencem à União o mar territorial e os potenciais de energia hidráulica, onde podem ser instaladas hidroelétricas para geração de energia. Aos Estados resta o domínio das águas superficiais ou subterrâneas, fluentes, emergentes e em depósito, ressalvadas, neste caso, as decorrentes de obras da União.

Ainda, no que se refere à competência para legislar sobre a água, o art. 22, IV, confere tal prerrogativa à União, privativamente, no que se refere a regras de natureza civil. Autoriza-se, portanto, que os Estados estabeleçam normas administrativas e de gestão sobre os bens sob seu domínio, o que inclui os recursos hídricos (GRANZIERA, 2015, p. 278). Dessa forma, como podemos observar, há no Brasil uma gestão descentralizada deste recurso, o que permite a existência tanto de uma Política Nacional quanto de diversas Políticas Estaduais de Recursos Hídricos.

Em razão desta divisão de domínio, e conforme previsão constitucional expressa, ${ }^{5}$ coube à União instituir o Sistema Nacional de Recursos Hídricos e definir critérios de outorga de direitos de uso destes recursos. Em 1997 foi editada a Lei no 9.433 que instituiu referido sistema e é ainda hoje a responsável por regulamentar o uso das águas no Brasil. O Sistema Nacional de Recursos Hídricos é o responsável por coordenar a gestão integradas das águas e é composto por órgãos colegiados, pela Administração Pública e por organizações civis de recursos hídricos. Tanto a União quanto os Estados possuem representantes neste sistema, para que a gestão da água seja realizada da forma mais harmoniosa possível.

No que se refere à outorga do direito de uso de recursos hídricos e a cobrança que pode ser realizada em razão deste uso, alguns órgãos do sistema são de importante destaque. Dentre os órgãos colegiados está o Conselho Nacional de Recursos Hídricos $(\mathrm{CNRH})$, responsável, entre outras atribuições, por estabelecer critérios gerais para a outorga de direitos de uso da água e para a cobrança por este uso. Ainda, também

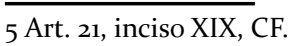


encontramos entre os órgãos colegiados os Comitês de Bacia Hidrográfica, criados justamente para os casos em que uma bacia hidrográfica possui águas tanto de domínio da União quanto dos Estados. Estes comitês são formados por representantes de ambos os entes públicos, além de representantes dos Municípios atingidos, dos usuários das águas e de entidades civis de recursos hídricos que possuam atividade na respectiva bacia, permitindo assim, uma gestão equilibrada. Dentre suas competências está a fixação de mecanismos de cobrança pelo uso de recursos hídricos e sugestão de valores a serem cobrados, para encaminhamento ao CNRH ou aos Conselhos Estaduais que são os responsáveis pela aprovação desses mecanismos e valores propostos.

Por fim, também é responsável pela gestão do uso dos recursos hídricos a ANA, Agência Nacional de Águas, entidade pública que tem como atribuição a supervisão, o controle e a avaliação das ações e atividades pertinentes aos recursos hídricos, principalmente no que se refere ao poder de polícia, sendo de sua responsabilidade a outorga, através de autorização, do direito de uso de recursos hídricos em corpos de água de domínio da União. A ANA ainda é responsável pela arrecadação, distribuição e aplicação das receitas auferidas com a cobrança pelo uso destes recursos. Tal cobrança não poderá ser realizada por entidades de direito privado, vez que os recursos auferidos são de natureza pública, na forma de preço público, portanto, impossível que seja realizada pelos órgãos colegiados supracitados, que possuem uma parcela de entidades privadas em sua composição.

Importante salientar que a água, como bem de uso comum do povo, pode ser usufruída por qualquer indivíduo. Entretanto, a outorga de direito de uso se faz necessária para o estabelecimento de condições e limites na medida em que se objetiva o uso privado deste recurso, vez que neste caso se está impossibilitando que os demais também o utilizem. Para que estas outorgas fossem adequadamente geridas, a mesma lei que criou o Sistema Nacional de Recursos Hídricos, a Lei no 9.433/97, também instituiu a Política Nacional de Recursos Hídricos brasileira, prevendo nela instrumentos de planejamento, decontrolee instrumentos econômicos utilizados para a gestão da água. A implementação destes instrumentos compete aos referidos órgãos e entidades, públicas e privadas, que compõe o Sistema Nacional (GRANZIERA, 2015, p. 286), e um dos instrumentos econômicos previstos é a cobrança pelo uso de recursos hídricos, que objetiva dar ao usuário uma indicação do valor real da água, incentivar sua racionalização e, ainda, obter recursos financeiros para o financiamento de programas e intervenções para gestão e preservação deste recurso natural. A aplicação deste instrumento econômico específico será melhor explorada no tópico a seguir.

\subsection{Do instrumento de cobrança pelo uso dos recursos hídricos e sua insuficiência.}

Conforme explanado no ponto anterior, um dos instrumentos da Política Nacional de Recursos Hídricos é a cobrança pelo uso destes recursos com vistas a indicar ao usuário o valor real da água, incentivar sua racionalização e, por fim, obter recursos financeiros para o financiamento de programas e intervenções. Ainda, a Resolução do Conselho 
Nacional de Recursos Hídricos (CNRH) no 48 de 2005 acrescentou mais dois objetivos para este instrumento, sendo um deles o de induzir e estimular a conservação, o manejo integrado, a proteção e a recuperação dos recursos hídricos. Dessa forma, pode-se utilizar a cobrança pelo uso da água como instrumento de indução de comportamentos, de maneira a estimular a racionalização deste recurso natural.

A quantidade de água existente em nosso planeta permanece a mesma desde o surgimento dos primeiros seres vivos. Entretanto, tendo em vista o crescimento populacional desmoderado, o consumo desta água pelas diferentes atividades humanas aumentou em sete vezes nos últimos 60 anos (WHATELY, 2017). Vivemos atualmente, portanto, em um chamado estresse hídrico, onde os diversos usos que o ser humano faz da água não são compatíveis com a disponibilidade natural da mesma. O consumo humano de água para alimentação, higiene e produção industrial são classificados pela doutrina como parcialmente consuntivos, ou seja, uso que devolve parte da água utilizada aos rios na forma de esgotos e efluentes industriais (VARGAS, 1999, p. 109-134), diferentemente do que ocorre com a irrigação na agricultura, considerada atividade de uso totalmente consuntivo. De qualquer forma, essa classificação não leva em conta o impacto que o uso humano tem sobre a água, vez que a devolução da mesma na forma de esgoto e efluentes industriais pode contribuir para a poluição e perda de qualidade de mananciais inteiros quando mal executada.

Ainda, temos que levar em consideração que uma porcentagem considerável deste consumo pelo ser humano se deve a vazamentos, submedições e fraudes. Estimase que, em média, nas 27 capitais brasileiras, $45 \%$ da água retirada dos mananciais são desperdiçadas. A quantidade de água jogada fora é estimada em 6,14 bilhões de litros por dia e seria suficiente para atender ao consumo diário de 38 milhões de pessoas (WHATELY, 2017). O uso desmedido da água também é preocupante no país. A ONU recomenda o consumo diário per capita de 110 litros, enquanto que a média per capita brasileira nas capitais é de 150 litros por dia e em cidades como São Paulo, Rio de Janeiro e Vitória esses números chegam a 220 litros por dia por habitante.

O uso excessivo doméstico se torna irrelevante perto do imenso desperdício praticado pela indústria, agricultura e pecuária. No Brasil, $72 \%$ da água disponível é utilizada para irrigação e, de acordo com pesquisa dirigida pela FAO (sigla em inglês para Organização das Nações Unidas para a Alimentação e Agricultura) (WALBERT, 2013), cerca de $60 \%$ da água utilizada é perdida em razão dos métodos adotados. A pesquisa ainda aponta que caso este desperdício fosse reduzido em, no mínimo, 10\%, seria possível abastecer o dobro da população mundial nos dias atuais. Necessário, portanto, que as ações governamentais tenham também foco especial nestes setores. ${ }^{6}$

A consequência dos supracitados hábitos domésticos e mercantis é a de que o Brasil, detentor de $12 \%$ da água doce do planeta como já expusemos, disputa com o México o troféu de quem desperdiça mais água limpa no mundo (WHATELY, 2017). Tendo estes dados em mente e considerando o reconhecimento do direito à água como um direito

6 Interessante observar que a Política Nacional de Recursos Hídricos, em seu art. 1º, inciso III, define que em situações de escassez, o uso prioritário dos recursos hídricos é o consumo de humanos e de animais, o que exigiria um racionamento na indústria antes de um racionamento doméstico. 
fundamental e a forma como a mesma é regulamentada no país, resta-nos questionar que tipo de ação deve ser tomada para lograr preservar recurso natural tão essencial.

Maria Luiza Machado Granziera acerta quando expõe em sua obra que o direito deve impor para a utilização da água:

(...) restrições, seja de cunho administrativo, seja de natureza financeira, como é o caso da cobrança pelo uso dos recursos hídricos, com vistas a proceder ao controle do uso e evitar a escassez e injustiças, como a falta de acesso à água para as necessidades básicas, como o consumo humano (GRANZIERA, 2015, p. 282).

A Política Nacional de Recursos Hídricos, em seu art. 2º̄, prevê como objetivo assegurar à atual e às futuras gerações a necessária disponibilidade de água, em padrões de qualidade adequados aos respectivos usos. Para que se alcance esse objetivo, poder-se-ia utilizar a já mencionada cobrança pelo uso da água, vez que se objetiva através da implementação deste instrumento, entre outras coisas, uma mudança no comportamento do usuário. Destaca-se que esta cobrança é preço público, não um imposto, e seu produto tem aplicação vinculada à projetos e obras específicos a serem realizados, prioritariamente, na bacia hidrográfica em que foram gerados.

Ocorre que, atualmente, em rios de domínio da União, a cobrança pelo uso da água já foi implementada na Bacia do Rio Paraíba do Sul, nas Bacias dos Rios Piracicaba, Capiviri e Jundaí, na Bacia do Rio São Francisco e na Bacia do Rio Doce. Recentemente a Bacia do Rio Paranaíba também foi incluída e passou a cobrar pelo uso da água desde 10 de março de 2017, conforme Resolução no 185/2016 do CNRH (AGÊNCIA NACIONAL DE ÁGUAS, 2017a). Diversos Estados também já implementaram este instrumento como o Rio de Janeiro, São Paulo, Paraná e Ceará (AGÊNCIA NACIONAL DE ÁGUAS, 2017b).

Tendo em vista a crise da água vivenciada recentemente pela população, principalmente no Estado de São Paulo, percebe-se que a cobrança não obteve grandes resultados no que se refere ao induzimento no racionamento da água. A própria Agência Nacional de Águas disponibilizou relatório para avaliação da implementação da cobrança na Bacia do rio Paraíba do Sul, compreendendo o período de 2003 a 2011, no qual fica perceptível que a captação de água permaneceu praticamente constante após a implementação da sua cobrança, havendo apenas uma pequena redução no consumo, quase irrelevante (AGÊNCIA NACIONAL DE ÁGUAS, 2012).

Uma das razões possíveis para que este instrumento econômico não esteja alcançando seu objetivo no induzimento ao racionamento e preservação pelos usuários dessas bacias é a de que seu valor ainda é considerado irrelevante pelos mesmos, não os afetando suficientemente para que modifiquem suas condutas. Dessa forma, é premente a necessidade de se pensar em outras possibilidades de indução de comportamento, motivo pelo qual o desenvolvimento do presente trabalho se demonstra necessário.

\section{TRIBUTAÇÃO DA ÁGUA?}

Tendo em vista a necessidade urgente de proteção da água em razão de sua indiscutível importância para a humanidade, a fundamentalidade do acesso a este bem, 
vez que o mesmo é responsável por garantir outros direitos fundamentais como o direito à vida digna e saudável, e a ineficácia visível dos instrumentos econômicos já aplicados no país com intuito de incentivar o seu racionamento, questiona-se: seria possível a tributação dos serviços de fornecimento de água potável ou da própria água objetivando a indução de uma conduta mais sustentável por parte da população? Essa indagação tem sido cada vez mais frequente no meio acadêmico, razão pela qual é foco central de estudo desta pesquisa.

\subsection{O princípio da tributação sustentável}

A tributação possui duas funções destacadas no Estado Democrático de Direito. De um lado, uma função arrecadatória e de outro uma função extrafiscal. A função arrecadatória tradicionalmente tem sido considerada a função principal dos tributos, de tal modo que as políticas públicas devem ser realizadas mediante a concretização de gastos públicos democraticamente definidos na lei orçamentária (CALIENDO; MUNIZ; RAMME, 2014, p. 471-491).

O orçamento público deve apresentar detalhadamente as despesas a serem realizadas e as receitas necessárias para cumprir com as tarefas constitucionais. $\mathrm{O}$ legislador deve, para esta concepção, eleger os fatos econômicos passíveis de tributação, que irão se constituir em fatos jurídicos-tributáveis. O cálculo da receita necessária para as tarefas públicas é objeto de ajuste, por conta da Ciência das Finanças, e de normatização pelo Direito Financeiro. Ajustar-se-ão alíquotas, base de cálculo, hipóteses de incidência conforme a política fiscal necessária. Assim, na política fiscal ambiental levar-se-á em conta os valores necessários para fazer frente aos desafios de prevenção, proteção e recuperação do meio ambiente, especialmente, por meio de ação pública.

O Direito Tributário nessa concepção clássica não se preocupa com os fatos eleitos, nem com suas razões econômicas e financeiras. O fato jurídico-tributário é o resultado de um processo democrático, público e legítimo derivado de um longo processo de seleção entre escolhas competitivas. O legislador ao determinar a incidência da norma sobre determinado evento econômico decidiu dentre diversas variáveis econômicas, financeiras e técnicas, por aquela capaz de permitir a solução mais adequada e eficiente para o atingimento do fim pretendido.

A intepretação tributária tradicional busca esclarecer, do modo mais preciso possível, qual o momento de incidência jurídica, bem como o preenchimento científico dos componentes normativos. Não é sua tarefa perquirir os efeitos da tributação, nem tampouco a destinação dos recursos arrecadados. Essa é a função do Direito Financeiro, e, assim, cada especialidade deve realizar o melhor de sua ciência na busca de seus propósitos.

O Direito Tributário é orientado por rigorosos requisitos de análise sobre a incidência da norma tributária e sobre os limites constitucionais do poder de tributar. As intrincadas normas de repartição de competência são, por si só, um gigantesco desafio posto aos tributaristas. A correta determinação da regra de competência exige a análise de todo um conjunto de fatores que provocam a incidência formal da norma tributária. 
Sem estes elementos rigorosamente preenchidos, não irá se processar o fenômeno de imposição fiscal (CALIENDO, 2009).

A interpretação clássica deparou-se com novos e importantes desafios. Coube à doutrina destacar, que além dos clássicos problemas de ocorrência do fato gerador, outros, tão relevantes quanto, mereciam, igualmente, a atenção dos juristas. Tratase do problema da eficácia normativa. Não basta questionar o fenômeno isolado da subsunção, quando esta, para se realizar, deve obedecer a diversos limites formais e materiais de incidência. A regra deve ser editada por autoridade competente, mas deve igualmente respeitar limites materiais, tais como: o princípio da capacidade contributiva, da isonomia, da essencialidade, da proporcionalidade e tantos outros. As limitações materiais ao poder de tributar se demonstraram tão importantes, quanto as limitações formais e de competência.

Os desafios do controle material exigiriam uma nova teoria tributária. Não bastaria olhar a estrutura normativa, seria necessário verificar os fins pretendidos. $\mathrm{O}$ estudo da eficácia normativa demanda novos e importantes instrumentos de análise, uma nova metodologia, novas abordagens, a observação dos estudos em outras ciências e assim por diante.

A norma tributária não poderia ser mais interpretada em sua solidão tributária, mas sim ser esquadrinhada no contexto constitucional onde os princípios constitucionais emanam sentido para todo o sistema. $\mathrm{O}$ reducionismo estruturalista impedia a correta compreensão do fenômeno da concreção normativa. A norma individual e concreta não era mais resultado de uma operação lógica de mera subsunção do fato à norma, mas o resultado complexo da ponderação de regras, princípios e valores normativos. Mesmo os casos simples demonstrariam a situação onde a ponderação e hierarquização normativoaxiológica já estariam previamente definidas.

No modelo clássico, as ponderações e hierarquizações valorativas já estavam previamente resolvidas pela política fiscal, sob os auspícios da Ciência das Finanças e do Direito Financeiro. Não havia sentido em se reabrir esses dilemas. Os fins competitivos haviam sido analisados e o fim pretendido escolhido, selecionado dentre tantas outras possibilidades, com metodologia adequada. Seria uma pretensão do Direito Tributário, com seu instrumental analítico querer invalidar as escolhas anteriormente tomadas, democraticamente realizadas.

O grande dilema decorre de uma sociedade complexa, onde a legislação e a Constituição, permitem a permanência legítima de fins distintos nos textos normativos. Exige a proteção da liberdade, mas demanda a promoção da igualdade. Protege a propriedade, mas demanda sua função social. O choque estrutural entre modelos distintos é o signo dos textos constitucionais contemporâneos. De um lado, resguardase a autonomia privada, de outro a preservação do bem comum. Dois grandes princípios implícitos irão emergir desse delicado equilíbrio: subsidiariedade e solidariedade.

O princípio da subsidiariedade invoca a responsabilidade individual para a definição dos meios a serem realizados para a determinação das melhores escolhas. Há uma crença de que as decisões individuais irão convergir para soluções ótimas para 
todos. Se cada um for deixado livremente para definir seus objetivos e metas, o resultado será melhor para todos. O indivíduo que buscar a melhor saúde, educação, habitação e outros bens pessoais, irá inconscientemente dirigindo a sociedade para um patamar melhor.

De outro lado, o princípio da solidariedade indica que o mecanismo de escolhas individuais ótimas pode falhar por diversas razões: falta de informações, de educação, estrutura social estratificada, desigualdades regionais e sociais, concentração do poder político, discrepância de objetivos comuns entre gerações e classes. A solidariedade surge como um contraponto e como uma correção às falhas da autonomia individual. Em alguns casos, a busca exclusiva de interesses pessoais pode no longo prazo gerar um prejuízo geral. Esse é o famoso dilema apontado pela "tragédia dos bens comuns" ("tragedy of the commons"), proposta por Garrett Hardin, que demonstrou que determinados bens exigem um modelo distinto de proteção (HARDIN, 1968, p. 1243-1248).

A teoria econômica demonstrou igualmente que pode ser interesse individual participar de escolhas colaborativas. Nem sempre os objetivos individuais podem ser alcançados por esforço e responsabilidade meramente individual, exigindo ações coordenadas. Esse é o clássico exemplo da caça ao servo e do teorema de Nash. Nos dois casos, se demonstra que a ação conjunta pode trazer resultados individuais superiores à ação individual (CALIENDO, 2008).

Demonstrada a legitimidade e coerência do princípio da solidariedade e da subsidiariedade, cabe ressaltar, que ambos devem estar em sintonia e equilíbrio, não sendo o caso desse artigo perguntar-se sobre a sua compatibilização no texto constitucional.

A doutrina tributária viu-se pressionada a abarcar um conjunto teórico muito novo, instigante e complexo. Não bastava estudar a estrutura da norma, mas igualmente os seus efeitos normativos. Os fins internos e fins externos pretendidos. Como realizar isso sem decair em um sincretismo metodológico? Em um mal-uso dos conceitos econômicos e financeiros? A interpretação do fenômeno jurídico deveria aceitar as contribuições de uma análise econômica e social. Não se trata de uma corrupção ou submissão do jurídico ao social e político, mas de uma abertura metodológica, que aceita os influxos externos e os reinterpreta conforme uma teoria sistemática do Direito Tributário.

O tributo passa a ser percebido em outra dimensão, além da fiscal, assim, a doutrina irá ocupar-se dos efeitos extrafiscais das normas tributárias. A interpretação sistemática reivindica que a sustentabilidade seja adotada como valor (axiológico) e princípio (deontológico) explícito, ao constar, no próprio preâmbulo da $\mathrm{CF} / 88$, o dever de desenvolvimento, cuja concretização normativa extrai-se dos arts. $3^{\circ}$, II, 174, parágrafo único (planejamento e desenvolvimento equilibrado), art. 192 (sistema financeiro tem de promover o desenvolvimento que serve aos interesses da coletividade), art. 205 (vinculado ao pleno desenvolvimento da pessoa); art. 218 (desenvolvimento científico e tecnológico com o dever de observar os limites ecológicos) e art. 219 fixando, de forma indelével, o compromisso da República Federativa do Brasil de promover o desenvolvimento por esse caminho.

Tanto é assim que se considera uma das principais inovações da Constituição 
Federal de 1988, em face da Constituição de 1967, justamente a fixação do dever estatal de promover a proteção ambiental. Tal dever passou a constar, de forma expressa, no art. 225, no sentido de que "todos tem direito ao meio ambiente ecologicamente equilibrado, bem de uso comum do povo e essencial à qualidade de vida, impondo-se ao Poder Público e à coletividade o dever de defende-lo e preservá-lo para as presentes e futuras gerações”, sendo conjugado com o art. 170, que dispõe no seguinte sentido:

Art. 170. A ordem econômica, fundada na valorização do trabalho humano e na livre-iniciativa, tem por fim assegurar a todos existência digna, conforme os ditames da justiça social, observados os seguintes princípios: [...] VI - defesa do meio ambiente, inclusive mediante tratamento diferenciado conforme $o$ impacto ambiental dos produtos e serviços e de seus processos de elaboração e prestação; (BRASIL, 2003).

Refere-se que a proteção do meio ambiente aparece reforçada em diversos dispositivos constitucionais, tais como nos artigos que tratam da competência da União (art. 21, incs. XIX e XX e 22, incs. IV, XII e XXVI), na competência material comum (art. 23, incs. III, VI, VII, IX e XI) e nas competências legislativas concorrentes (art. 24, incs. VI, VII e VIII), bem como em outros dispositivos específicos. Esses, por sua vez, estão relacionados à sustentabilidade em geral; assim, exemplificativamente, encontramos o dispositivo que trata do planejamento e desenvolvimento equilibrado (art. $3^{\circ}$., inc. II, 174, parágrafo único), que dá atribuição ao sistema financeiro de promover o desenvolvimento que serve aos interesses da coletividade (art. 192), desenvolvimento científico e tecnológico, com o dever de observar os limites ecológicos (art. 218), entre tantos.

A defesa do meio ambiente impõe a proteção constitucional de um bem imaterial de propriedade comum de todos, tratando-se de um legítimo bem público a ser protegido por toda a coletividade.

Como consequência da orientação traçada pelo Constituinte, a legislação infraconstitucional consagrou essa proteção em diversas leis, tais como o Código Florestal, a Lei sobre a Política Nacional de Meio Ambiente, entre outras. Em especifico, refere-se o art. 99, inc. I, do Código Civil que determina que são bens públicos: "I os de uso comum do povo, tais como rios, mares, estradas, ruas e praças". Observase, portanto, que os dispositivos constitucionais e legais referidos demonstram que a corresponsabilidade de todos na proteção de um patrimônio comum exige uma postura cooperativa. Nesse contexto, o dever de solidariedade se impõe, definindo o objetivo de proteção de benefícios e responsabilidades compartilhadas.

Infere-se, a partir desse espectro normativo, a obrigatoriedade tanto do Estado, em suas diversas esferas, como dos cidadãos, de adoção de medidas que "promovam, a longo prazo, o desenvolvimento propício ao bem-estar pluridimensional (social, econômico, ético, ambiental e jurídico-político)", que compõe o atual conceito de sustentabilidade.

Sob a perspectiva do Direito Constitucional Tributário, o valor mote da concretização da sustentabilidade, como princípio ordenador, corresponde ao dever de solidariedade fiscal, que correlaciona o dever de pagar tributos à promoção dos direitos 
fundamentais. Nesse contexto, a solidariedade influencia na liberdade, na medida em que estabelece um vínculo de fraternidade entre os que participam do grupo beneficiário de prestações positivas, máxime as relacionadas com os mínimos sociais e com os direitos difusos.

Ainda sob a perspectiva constitucional-fiscal, impõe-se referir que o princípio da sustentabilidade está relacionado diretamente com os princípios da prevenção e precaução, que orientam o sistema a partir de preceitos éticos e jurídicos, decorrentes da sociedade de risco, quais sejam: transparência, responsabilidade, precaução, prevenção, solidariedade social e solidariedade do grupo.

Nesse sentido, a promoção de medidas indutoras de comportamentos que valorizem os vínculos de solidariedade constitui-se no dever de que não se pode olvidar o Poder Público sob pena de incidir em omissão odiosa. Além disso, na atenção especifica deste artigo, decorre do princípio da sustentabilidade, em correlação com os princípios da prevenção e precaução, a necessidade de acolher o caráter preferencial da proteção da água potável.

\subsection{A tributação sustentável da água}

O problema do presente estudo se direciona à indagação de como a tributação da água potável poderia auxiliar na preservação desse bem de uso comum. Diversas abordagens relacionadas, igualmente importantes, não serão objeto de consideração, tais como: tributação da água mineral, do tratamento dos esgotos cloacais e pluviais, do saneamento básico e das normas sobre inovação tecnológica, na proteção da água. Não serão também objeto de estudo as medidas de proteção tributária dos rios, mares e demais cursos d'água, mas tão somente a tributação do fornecimento de água potável. A escolha desse tema específico, como já mencionado, justifica-se pela importância da água potável para uma vida digna, bem como pela fragilidade na sua proteção.

Antes de mais nada, imperioso discorrermos acerca da natureza que possui a remuneração pelo fornecimento de água potável. De pronto, considerar-se-ia que referida remuneração teria natureza de taxa. As taxas são tributos específicos e divisíveis, nos termos do art. 145 da CF/88, que determina em seu inciso II que as mesmas podem ser cobradas: "em razão do exercício do poder de polícia ou pela utilização, efetiva ou potencial, de serviços públicos específicos e divisíveis, prestados ao contribuinte ou postos à sua disposição”. A taxa de fornecimento de água potável, portanto, pode ser classificada como uma espécie de taxa de serviço, tendo em vista que o CTN, em seu art. 79, disciplina os serviços públicos como sendo aqueles utilizados pelo contribuinte: a) efetivamente, quando por ele usufruídos a qualquer título ou b) potencialmente, quando, sendo de utilização compulsória, sejam postos à sua disposição mediante atividade administrativa em efetivo funcionamento. Ainda, os serviços públicos podem ser: a) específicos, quando possam ser destacados em unidades autônomas de intervenção, de utilidade ou de necessidade públicas; ou c) divisíveis, quando suscetíveis de utilização, separadamente, por parte de cada um dos seus usuários. 
Entretanto, além da possibilidade da taxa de serviço, de acordo com o STJ, a remuneração pelo fornecimento de água potável pode ser realizada por meio de preços públicos (tarifas), quando o serviço for prestado por particulares, por meio de concessão ou permissão pública. Dessa forma, não há a obrigatoriedade de que o serviço seja prestado exclusivamente pelo Poder Público. O STJ firmou este entendimento na Súmula 407, ao determinar que "é legítima a cobrança da tarifa de água, fixada de acordo com as categorias de usuários e as faixas de consumo".

Ives Gandra Martins ressalta que não basta a caracterização do fornecedor do serviço para a determinação da natureza do tributo, sendo necessária também uma análise do vínculo estabelecido. Se a prestação for compulsória pelo Estado e não houver espaço para a voluntariedade na contratação, então o serviço é público e a remuneração cobrada será taxa e não preço público. O STJ já se posicionou ressaltando o interesse público no fornecimento privado de água, mas entendendo como legítima sua prestação privada e com remuneração mediante preços públicos porque, assim, estimula-se o uso racional dos recursos hídricos, especialmente, quando há cobrança escalonada e conforme categorias de usuários. ${ }^{7}$

Superada esta discussão, passa-se a análise da possibilidade de incidência do ICMS sobre este fornecimento com finalidade extrafiscal. Em relaçãoà esta problemática, o STF já se posicionou, no julgamento do RE n. 607056, com repercussão geral já reconhecida, decidindo que o referido imposto não pode incidir sobre o fornecimento de água encanada. No caso concreto, o Estado do Rio de Janeiro alegava a possibilidade de incidência do ICMS, sob o argumento de que a água encanada não poderia ser considerada como um serviço público essencial, no sentido próprio, dado que estaria sujeita ao corte em caso de inadimplência do usuário. No entender do fisco estadual, a água poderia ser considerada como mercadoria, por ser bem corpóreo, fungível, consumível e transferível onerosamente, não se encontrando fora do comércio.

O STF adotou a tese exarada pelo relator, Min. Dias Toffoli, no sentido de determinar a natureza essencial do serviço à população. Para o redator do voto-vista, o Min. Luiz Fux, a água deve ser sim considerada como bem público de uso comum do povo, situando-se fora do conceito de mercadoria. Para o ministro, o fato de se pagar preço público pelo seu fornecimento não implica em uma assunção de sua natureza como bem precificável, tratando-se tão somente de medida de proteção eficaz deste bem, face ao risco de seu racionamento. Firmou-se, portanto, na Corte, posição para afastar a incidência do ICMS sobre o fornecimento de água encanada, seguindo as orientações anteriores do STF. ${ }^{8}$

Votaram em sentido divergente o Min. Marco Aurélio e o Min. Ricardo Lewandowski, que defenderam que a tributação da água encanada permitiria um uso mais racional desse bem escasso, alertando ainda para a distinção entre a proteção da água in natura como bem comum do povo e a água tratada, quimicamente e com outros procedimentos, que implicaria em um bem distinto.

7 AgRg no Ag 1084537/RJ , $1^{\underline{a}}$ T., Min. Teori Albino Zavascki, DJe de 18 fev. 2009.

8 ADIs 567 e 2224 . 
Em nosso entender, considerar a água encanada como mercadoria, não atingiria o objetivo almejado, visto que o valor arrecadado pela tributação da água serviria tão somente para o custeio da máquina pública e não possuiria sentido extrafiscal de proteção. E caso fosse considerada como mercadoria essencial, então deveria estar protegida pelo princípio da essencialidade e estaria necessariamente na cesta básica. De um modo ou outro, o objetivo não seria adequadamente alcançado. Talvez, dada a importância do tema, o fornecimento de água deva ser considerado como um serviço essencial de primeira grandeza, que exigiria uma solução diversa da consideração da água como mercadoria simplesmente.

Uma possibilidade que caberia ser questionada seria a instituição de uma Contribuição de Intervenção no Domínio Econômico, com sentido deproteção ambiental da água ou de outros bens naturais essenciais e esgotáveis. Essa alternativa seria permitida pelo art. 149 do texto constitucional. Assim, o novel tributo poderia ser instituído, desde que os recursos arrecadados possuíssem destinação específica de proteção ambiental. Entretanto, algumas críticas podem ser levantadas contra este tipo de proposta, como, por exemplo, a já existência de uma grande quantidade de tributos, o aumento da carga fiscal, o dano ao setor empresarial e produtivo que a instituição desta contribuição acarretaria, a dificuldade de um controle na destinação dos tributos vinculados, o caráter permanente dessas criações interventivas, dentre tantas outras. Tendo em vista o direito fundamental que se pretende proteger, no que pese serem consideráveis as desvantagens de instituição desta CIDE, ainda assim a opção não pode ser de pronto desconsiderada, devendo ser objeto de ponderação e maiores análises para uma possível aplicação.

Uma alternativa à instituição de uma Contribuição de Intervenção no Domínio Econômico seria a instituição de um imposto ambiental específico que deveria obedecer ao regime do art. 154, I da CF, que autoriza a instituição de novos tributos, desde que mediante lei complementar e desde que sejam não-cumulativos e não tenham fato gerador ou base de cálculo próprios dos discriminados na Constituição. Essa proposta esbarraria, contudo, na vedação de impostos com natureza sancionatória. Porém, importante salientar que existem exceções ao princípio da vedação ao confisco, como no caso dos tributos extrafiscais que não tem função arrecadatória, mas de instrumento de ação política, econômica ou social. Portanto, cabe ainda debater se a instituição de um imposto ambiental específico sobre o fornecimento de água, tendo finalidade prioritariamente extrafiscal, seria possível e contribuiria para a indução do racionamento deste recurso natural.

\section{CONSIDERAÇÕES FINAIS}

Percebe-se, após esta breve análise quanto às espécies tributárias que poderiam vir a incidir sobre o fornecimento de água potável com uma finalidade extrafiscal, que a proteção tributária da água é problema complexo que demanda absoluta prioridade na busca por soluções adequadas. As possibilidades apresentadas possuem vantagens e desvantagens e carecem de uma maior ponderação, tendo em vista a importância do direito fundamental em pauta. 
Certo équea água potável, como recurso natural indispensável para a sobrevivência humana, inclusive sendo elevada à direito humano pela Organização das Nações Unidas, requer uma maior proteção por parte do Estado. Ainda há indagações a respeito sobre qual tributo deve ser utilizado com finalidade de induzir o racionamento deste bem, porém, permanece a certeza de que o fornecimento deste recurso precisa ser controlado e melhor regulamentado, de maneira a garantir, inclusive para as gerações futuras, o seu acesso e, consequentemente, uma vida digna a todos.

\section{REFERÊNCIAS}

AGÊNCIA NACIONAL DE ÁGUAS, 2012. Avaliação da implementação da cobrança pelo uso de recursos hídricos de domínio da União na bacia hidrográfica do Rio Paraíba do Sul. Disponível em: < http://arquivos.ana.gov.br/institucional/sag/ CobrancaUso/Cobranca/RelatorioAvalImplCobPBSo3_11.pdf > . Acesso em: mar. 2017.

Cobrança pelo uso da água começa a valer na bacia do rio Paranaíba. 2017a.. Disponível em: < http://www2.ana.gov.br/Paginas/imprensa/noticia.aspx?id_ noticia $=13183>$. Acesso em: mar. 2017.

Cobrança pelo uso de recursos hídricos. 2017b. Disponível em: < http:// www2.ana.gov.br/Paginas/servicos/cobrancaearrecadacao/cobrancaearrecadacao.aspx >. Acesso em: mar. de 2017.

. Fatos e tendências:água. Brasília: Agência Nacional de Águas, 2009. Disponível em: < http://arquivos.ana.gov.br/imprensa/publicacoes/fatosetendencias/edicao_2.pdf $>$. Acesso em: mar. 2017.

BRASIL. Constituição (1988). Emenda Constitucional nº 42, de 19 de dezembro de 2003. Altera o Sistema Tributário Nacional e dá outras providências. Portal da Legislação, Brasília, dez. 2003. Disponível em: < http://www.planalto.gov.br/ccivil_o3/constituicao/ emendas/emc/emc42.htm >. Acesso em: mar. 2017.

BRUNONI, Nivaldo. A Tutela das águas pelo município. In: FREITAS, Vladimir Passos de (Coord.). Águas: aspectos jurídicos e ambientais. Curitiba: Juruá, 2000.

CALIENDO, Paulo;MUNIZ, Veyzon Campos; RAMME, R.S..Tributaçãoesustentabilidade ambiental: a extrafiscalidade como instrumento de proteção do meio ambiente. Revista de direito ambiental, v. 76, p. 471-491, 2014.

. Direito tributário: três modos de pensar a tributação. Elementos para uma teoria sistemática do direito tributário. 1. ed. Porto Alegre: Livraria do Advogado, 2009. v. 1.

. Direito tributário e análise econômica do Direito - uma visão crítica. 1. ed. São Paulo: Campus/Elsevier, 2008. v. 1. 
CARLI, Ana Alice de. Água e seus instrumentos de efetividade: Educação Ambiental, Normatização, Tecnologia e Tributação. Campinas: Milennium, 2013.

COÊLHO, Sacha Calmon Navarro. Serviços públicos e tributação. In:TÔRRES, Heleno Taveira (Coord.). Serviços Públicos e Direito Tributário. São Paulo: Quartier Latin do Brasil, 2005.

GRAF, Ana Cláudia Bento. Água, bem mais precioso do milênio: o papel dos Estados. Revista CEJ, Brasília, n. 12, p. 30-39, set./dez. 2000.

GRANZIERA, Maria Luiza Machado. Direito ambiental. São Paulo: Atlas, 2015.

HARDIN, G. The tragedy of the commons Science. v. 162, p. 1243-1248, 1968.

SARLET, Ingo Wolfgang; FENSTERSEIFER, Tiago. Direito constitucional ambiental: constituição, direitos fundamentais e proteção do ambiente. São Paulo: Editora Revista dos Tribunais, 2013.

. Direto ambiental: introdução, fundamentos e teoria geral. São Paulo: Saraiva, 2014.

SILVA, Carla Adriana Basseto da. A natureza jurídica da remuneração dos serviços públicos de abastecimento de água e coleta de esgoto - Taxa ou preço público? Disponível em < http://www.semasa.sp.gov.br/Documentos/ASSEMAE/Trab_5o/pdf >. Acesso em: 09 set. 2006.

VARGAS, Marcelo Coutinho. O gerenciamento integrado dos recursos hídricos como problema socioambiental. Revista ambiente \& sociedade, Campinas, no ${ }^{\text {, }}$, p. 109-134, 1999. Disponível em: < http://www.scielo.br/scielo.php?script=sci_arttext\&pid=S1414753X1999000200009\&lng=pt\&nrm=iso\&tlng=pt >. Acesso em: mar. 2017.

VIEGAS, Eduardo Coral. Visão jurídica da água. Porto Alegre: Livraria do Advogado, 2005.

WALBERT, Allan. Agricultura é quem mais gasta água no Brasil e no mundo. Disponível em: < http://www.ebc.com.br/noticias/internacional/2013/o3/agriculturae-quem-mais-gasta-agua-no-brasil-e-no-mundo >. Acesso em mar. 2017.

WHATELY, Marussia. Haverá água para todos? Disponível em: < http://diplomatique. org.br/havera-agua-para-todos/ >. Acesso em: mar. 2017. 